\title{
Factors Associated With Viral Suppression and Rebound Among HIV Patients On Treatment: A Retrospective Study in Ghana
}

\section{Stephen Opoku ( $\nabla$ Ostephen275@gmail.com )}

Kwame Nkrumah University of Science and Technology School of Medical Sciences

https://orcid.org/0000-0002-1949-2338

\section{Samuel Asamoah Sakyi}

Kwame Nkrumah University of Science and Technology

Nana Kwame Ayisi-Boateng

Kwame Nkrumah University of Science and Technology

Anthony Kwame Enimil

Komfo Anokye Teaching Hospital

Ebenezer Senu

Kwame Nkrumah University of Science and Technology

\section{Richard Owusu Ansah}

Kwame Nkrumah University of Science and Technology

Bismark Dankwah Aning

Kwame Nkrumah University of Science and Technology

Diana Atsieno Ojuang

Kwame Nkrumah University of Science and Technology

\section{Doreen Nafula Wekesa}

Kwame Nkrumah University of Science and Technology

\section{Fatima Osman Ahmed}

Kwame Nkrumah University of Science and Technology

\section{Chidinma B. Okeke}

Kwame Nkrumah University of Science and Technology

\section{Ama Darkoaa Sarfo}

Komfo Anokye Teaching Hospital

\section{Research}

Keywords: HIV/AIDS, Viral suppression, viral rebound, Combined Antiretroviral Therapy (cART)

Posted Date: October 28th, 2021 
DOl: https://doi.org/10.21203/rs.3.rs-996319/v1

License: (c) (1) This work is licensed under a Creative Commons Attribution 4.0 International License. Read Full License 


\section{Abstract \\ Background}

Viral suppression remains the most desired outcome in the management of patients with Human Immunodeficiency Virus/Acquired Immune Deficiency Syndrome (HIV/AIDS) and this can be achieved by an effective combined Antiretroviral Therapy (CART). However, some patients who achieve viral suppression may experience viral rebound with dire consequence. We evaluated viral suppression and rebound and their associated factors among adult patients on cART in Kumasi, Ghana.

\section{Methods}

This hospital-based retrospective study was conducted at the Komfo Anokye Teaching Hospital in Ghana. We reviewed the medical records of 720 HIV patients on CART. Statistical analyses were performed using SPSS Version 26.0 and GraphPad prism version 8.0. $P<0.05$ was considered statistically significant.

\section{Results}

Proportions of patients with viral suppression and viral rebound were $76.1 \%$ and $21.0 \%$ respectively. Being diagnosed at $\mathrm{WHO}$ stage I [aOR=4.26,95\% Cl (4.20-48.44), $p<0.0001]$, having good adherence to ART [aOR=5.64, 95\% Cl (2.86-11.13), $p<0.0001]$, taking Nevirapine-based regimen [aOR=4.66, 95\% $\mathrm{Cl}(1.20-$ $18.04), p=0.0260]$ and increasing duration of treatment $(p<0.0001)$ were independently associated with higher odds of viral suppression. However, being diagnosed at WHO stage II (aOR=7.39, 95\%Cl: $2.67-$ $20.51 ; p<0.0001)$ and stage III (aOR=8.62, 95\% Cl: 3.16-23.50; $p<0.0001)$, having poor adherence $(\mathrm{aOR}=175.48,95 \% \mathrm{Cl}: 44.30-695.07 ; p<0.0001)$, recording baseline suppression value of 20-49 copies/mL $(\mathrm{aOR}=6.43,95 \% \mathrm{Cl}: 2.72-15.17 ; p<0.0001)$ and being treated with Zidovudine/Lamivudine/Efavirenz $(\mathrm{aOR}=6.49,95 \% \mathrm{Cl}: 1.85-22.79 ; p=0.004)$ and Zidovudine/Lamivudine/Nevirapine $(\mathrm{aOR}=18.68,95 \% \mathrm{Cl}$ : $1.58-220.90 ; p=0.02$ ) were independently associated with higher odds of viral rebound.

\section{Conclusion}

Approximately $76 \%$ viral suppression rate among HIV patients on CART in Kumasi falls below the WHO $95 \%$ target by the year 2030. Choice of ART combination, drug adherence, WHO clinical staging and baseline viral load are factors associated with suppression or rebound. These clinical characteristics of HIV patients must be monitored concurrently with the viral load.

\section{Introduction}

Human Immunodeficiency Virus/Acquired Immune Deficiency Syndrome (HIV/AIDS) is the leading cause of death and morbidity in the world [1]. In 2015, 38.8 million people were living with HIV and over a million 
deaths were attributed to HIV [2]. Sub-Saharan Africa is the most affected region with more than twothirds $(75 \%)$ of new HIV infections and $75 \%$ global HIV/AIDS deaths [2, 3]. Ghana has HIV prevalence of $1.7 \%$, affecting 334,713 people and accounting for over fourteen thousand annual deaths [4]. The Ahafo region (2.66\%) and the Lower Manya Krobo District (5.56\%) are the region and district with highest prevalence respectively, with the Ashanti region being the fifth HIV prevalent region (1.9\%) in Ghana [4].

In response to the global HIV/AIDS mortality and morbidity, the Joint United Nations Programme on HIV/AIDS (UNAIDS) launched the "90-90-90" targets in 2014, to help eradicate HIV as part of Sustainable Development Goals (SDGs) [5]. By 2020, it was expected that $90 \%$ of people who are infected with HIV should know their status through testing, of whom $90 \%$ individuals who know their status should be put on antiretroviral therapy and $90 \%$ of those on medication should achieve viral suppression. However, in respect to attaining the "90-90-90" target, global assessment has shown that, of all people living with HIV, $79 \%$ know their status, $62 \%$ are assessing antiretroviral therapy and $53 \%$ has achieved viral suppression [6]. In Western and Central Africa, $64 \%$ of People living with HIV (PLWH) know their status, $51 \%$ of HIV positive individuals are accessing antiretroviral therapy and only $39 \%$ experience suppression [6]. In Ghana, $57 \%$ know their status of which $34 \%$ are on cART. However, limited data is available on those who experience suppression and rebound [6].

The key focus on the fight against HIV/AIDS has been on the sustained Antiretroviral Therapy (ART), which has increased the success of viral suppression and continuous reduction in HIV/AIDS-related death [7]. Epidemiological studies have reported high rate of viral suppression among patients on first line ART, suggesting the hope of eradicating HIV if a streamlined care is utilized [8]. However, some people who achieve viral suppression are unable to maintain the viral load level and experience viral rebound [9].

Viral rebound increases vulnerability to other illnesses, treatment failure, CART resistance [10], and the potential for HIV transmission [11]. Again, viral rebound pose risk of increased HIV morbidity and mortality thereby hampering achieving United Nations agenda 90-90-90 targets and the eradication of AIDS by 2030. Although viral load uptake is common in Ghana, viral rebound following viral suppression has not received much attention. It is important to monitor these aspects of HIV/AIDS care to sustain the success achieved so far in the fight against HIV/AIDS.

Studies from other countries have related HIV viral suppression and viral rebound to numerous factors including adherence [11, 12], active tuberculosis [13], type of combination Antiretroviral therapy (cART) regimen $[11,14]$ and the socioeconomic status of the patient $[15,16]$. To our knowledge, no study has evaluated the viral rebound and its associated factors in Ghana. For the first time, we evaluated viral suppression and viral rebound and their associated factors among HIV patients on combination antiretroviral therapy (cART) at the Komfo Anokye Teaching Hospital in Ghana.

\section{Matrials And Methods}

\section{Study Design and Site}


This hospital-based retrospective study was conducted at the Komfo Anokye Teaching Hospital (KATH). Participants' data were retrieved from hospital archives and patients' folders. KATH is the second major tertiary Hospital in Ghana. The facility has over 1000 bed capacity and serves as a referral center for other hospitals in the middle and northern belts of Ghana.

\section{Study Population and Sampling}

The study population included registered HIV patients receiving cART at KATH from 2016-2020. Records of a total number of 5000 HIV patients over a five-year period were reviewed. Of the 5000 patients, 4,280 were excluded for not meeting inclusion criteria. Finally, 720 participants met the inclusion criteria and were included in the study. Of the 720 participants, 548 had achieved viral suppression and 172 did not achieve viral suppression. Of the 548 participants that achieved viral suppression, 115 experienced viral rebound and the remaining 433 maintained viral suppression [Figure 1].

\section{Sample Size Calculation}

The sample size was calculated using the online Calculator.net sample size calculator (https://www.calculator.net/sample-size-calculator.html). Where total population of 5000 registered HIV patients accessing the ART clinics of the three study sites from 2016 to 2020 with 95\% confidence level, $50 \%$ response distribution, and $5 \%$ margin of error were employed. Substituting these values, the minimum sample size required in this study was 357 . To increase statistical power, a total of $720 \mathrm{HIV}$ patients were included in the study.

\section{Inclusion/Exclusion Criteria}

All HIV-infected individuals 18 years and above, on cART for at least 6 months and with at least one valid report on viral load test were included in the study. All HIV-infected individuals below 18 years of age, HAART naïve or on cART and without viral load results were excluded.

\section{Collection of Sociodemographic and Clinical Data}

Medical files of study participants were inspected and information on age, gender, religion, level of education, occupation and marital status, history of co-infections, opportunistic infections, type of HIV infection, cART regimens, adherence to treatment, and WHO stages of HIV/AIDS abstracted. The date and time patients were diagnosed and started ART were recorded. The date and results of the first viral load test ( 6 months after diagnosis) was taken as the baseline viral load. Date and results of subsequent viral load tests (12 months, 24 months, 36 months and 48 months) were recorded.

\section{Definition of Viral Suppression, Viral Rebound, adherence to and durability of viral suppression.}

Viral suppression was defined as recording at least one viral load less than 50 copies/mL [17-20] whilst viral rebound was defined as recording at least one viral load $\geq 50$ copies $/ \mathrm{mL}$ after being suppressed [17, 18]. Adherence was defined by using pill counts. In pill count, patients bring back the actual pill containers 
to the HIV clinic in order to retrospectively assess the number of pills that remain in the patients' bottles. Patients were classified as good adherence if they do not miss pills in their history, fair adherence if they sometimes miss 1 or two pills and poor if they often miss more than two pills [21, 22]. Durability of viral suppression was defined as the length of time that patients on CART with viral load suppression will be able to maintain prior to viral rebound [23].

\section{Statistical Analysis}

Collected data obtained were entered, coded, edited, and cleaned in Microsoft Excel 2016. All statistical analyses were performed using the Statistical Package for Social Sciences (SPSS) Version 23.0 (Chicago IL, USA) and GraphPad Prism version 5.0 (GraphPad Software, San Diego California USA, www.graphpad.com). Data collected in this study were categorical data and were therefore presented as frequencies and percentages. A bar chart was used to illustrate the prevalence of viral suppression among study participants. Univariate logistic regression analysis was performed to screen for potential clinical and socio-demographic characteristics associated with viral suppression and viral rebound. Multivariate logistic regression model was used to determine independent predictors of viral suppression and viral rebound among HIV patients on treatment. P-values less than $0.05(p<0.05)$ were considered statistically significant.

\section{Results}

\section{Sociodemographic and Clinical Characteristics of Study Participants}

A total of 720 participants were included in the study. About one-third of the study participants were 30-39 years $(31.8 \%)$ or $40-49$ years $(32.5 \%)$. The majority of the patients in this study were females $(74.4 \%)$, married (44.6\%), have had junior high school (33.2\%) or primary school education $(22.1 \%)$, were working in the informal sector (73.2\%) or were Christians (85.4\%) (Table 1 ).

Majority of the patients were infected with HIV-1 (96.0\%), were diagnosed at WHO stage I (38.8\%) or stage III $(35.8 \%)$ or had no past ARV experience $(97.9 \%)$. More than half $(51.8 \%)$ of the patients had good adherence to ART, or have been on ARV treatment for 2 or more years (68.1\%). A few participants had other co-morbidities (11.1\%), opportunistic infections (10.8\%), or had ever stopped or changed ARV (7.6\%). The majority of the patients were on the Efavirenz-based regimen $(79.7 \%)$ and a few participants were on Lopinavir (PI)-based regimen (5.0\%). Again, more than half of the participants were taking TDF/3TC/EFV (69.6\%) as the specific ARV combination (Table 2). 
Table 1

Sociodemographic Characteristics of Study Participants

\begin{tabular}{|c|c|c|}
\hline Variable & Number of Participants $(n=720)$ & Percentage (\%) \\
\hline \multicolumn{3}{|l|}{ Age category (Years) } \\
\hline $18-29$ & 84 & 11.7 \\
\hline $30-39$ & 229 & 31.8 \\
\hline $40-49$ & 234 & 32.5 \\
\hline $50-59$ & 127 & 17.6 \\
\hline 60 and Above & 46 & 6.4 \\
\hline \multicolumn{3}{|l|}{ Gender } \\
\hline Male & 184 & 25.6 \\
\hline Female & 536 & 74.4 \\
\hline \multicolumn{3}{|l|}{ Marital Status } \\
\hline Married & 321 & 44.6 \\
\hline Single & 197 & 27.4 \\
\hline Cohabiting & 34 & 4.7 \\
\hline Widow/Widower & 75 & 10.4 \\
\hline Divorced & 93 & 12.9 \\
\hline \multicolumn{3}{|l|}{ Educational Level } \\
\hline No formal Education & 99 & 13.8 \\
\hline Primary School & 159 & 22.1 \\
\hline Junior High School & 239 & 33.2 \\
\hline Senior High School & 152 & 21.1 \\
\hline Tertiary Education & 71 & 9.9 \\
\hline \multicolumn{3}{|l|}{ Occupation } \\
\hline Unemployed & 126 & 17.5 \\
\hline Informal & 527 & 73.2 \\
\hline Formal & 67 & 9.3 \\
\hline \multicolumn{3}{|l|}{ Religion } \\
\hline Christian & 615 & 85.4 \\
\hline
\end{tabular}




\begin{tabular}{|lll|}
\hline Variable & Number of Participants $(\mathbf{n}=\mathbf{7 2 0})$ & Percentage $(\%)$ \\
\hline Muslim & 94 & 13.1 \\
\hline Traditionalist & 1 & 0.1 \\
\hline Other (Non-Affiliated) & 10 & 1.4 \\
\hline
\end{tabular}


Table 2

Clinical Characteristics of Study Participants

\begin{tabular}{|c|c|c|}
\hline Variable & Number of Participants $(n=720)$ & Percentage (\%) \\
\hline \multicolumn{3}{|l|}{ HIV Type } \\
\hline Type 1 & 691 & 96.0 \\
\hline Type 2 & 5 & 0.7 \\
\hline Type 1 and 2 & 24 & 3.3 \\
\hline \multicolumn{3}{|c|}{ WHO Stage of HIV } \\
\hline Stage I & 243 & 38.8 \\
\hline Stage II & 193 & 26.8 \\
\hline Stage III & 258 & 35.8 \\
\hline Stage IV & 26 & 3.6 \\
\hline \multicolumn{3}{|c|}{ Past ARV Experience } \\
\hline No & 705 & 97.9 \\
\hline Yes & 15 & 2.1 \\
\hline \multicolumn{3}{|c|}{ Adherence to ART } \\
\hline Good & 373 & 51.8 \\
\hline Fair & 254 & 35.3 \\
\hline Poor & 93 & 12.9 \\
\hline \multicolumn{3}{|c|}{ Presence of other conditions } \\
\hline No & 640 & 88.9 \\
\hline Yes & 80 & 11.1 \\
\hline \multicolumn{3}{|c|}{ Presence of opportunistic infection (s) } \\
\hline No & 642 & 89.2 \\
\hline Yes & 78 & 10.8 \\
\hline \multicolumn{3}{|c|}{ Ever Stopped or Changed ARV } \\
\hline No & 685 & 92.4 \\
\hline Yes & 55 & 7.6 \\
\hline
\end{tabular}

HIV; Human Immunodeficiency virus, WHO; world health organization, ARV; antiretroviral, CART; combination antiretroviral therapy, TDF; tenofovir, 3TC; lamivudine, EFV; efavirenz, ABC; abacavir, FTC; emtricitabine, NVP; nevirapine, AZT; zidovudine, LPV/r; lopinavir/ritonavir, DTG; dolutegravir. 


\begin{tabular}{|lll|}
\hline Variable & Number of Participants (n=720) & Percentage (\%) \\
\hline cARV Regimen & & \\
\hline Efavirenz-Based & 574 & 79.7 \\
\hline Nevirapine-Based & 63 & 8.8 \\
\hline Lopinavir (PI)-Based & 36 & 5.0 \\
\hline Integrase-Based & 47 & 6.5 \\
\hline ARV Combinations & & \\
\hline TDF/3TC/EFV & 501 & 69.6 \\
\hline TDF/FTC/EFV & 5 & 0.7 \\
\hline AZT/3TC/EFV & 44 & 6.1 \\
\hline ABC/3TC/EFV & 7 & 1.0 \\
\hline TDF/3TC/NVP & 34 & 4.7 \\
\hline TDF/FTC/NVP & 2 & 0.3 \\
\hline AZT/3TC/NVP & 44 & 6.1 \\
\hline TDF/3TC/LPV/r & 29 & 4.0 \\
\hline TDF/FTC/LPV/r & 4 & 0.6 \\
\hline AZT/3TC/LPV/r & 3 & 0.4 \\
\hline TDF/3TC/DTG & 47 & 6.5 \\
\hline HIV; Human Immunodeficiency virus, WHO; world health organization, ARV; antiretroviral, cART; \\
combination antiretroviral therapy, TDF; tenofovir, 3TC; lamivudine, EFV; efavirenz, ABC; abacavir, FTC; \\
emtricitabine, NVP; nevirapine, AZT; zidovudine, LPV/r; lopinavir/ritonavir, DTG; dolutegravir.
\end{tabular}

\section{Proportion of HIV viral Suppression and rebound among HIV patients of on Treatment}

Of the 720 participants that were analyzed in this study, the proportion of participants that achieved viral suppression (viral load $<50$ copies $/ \mathrm{mL}$ ) was $76.1 \%$ (Figure $2 \mathrm{~A}$ ). Of 540 participants who achieved viral suppression, 21.0\% experienced viral rebound (Figure 2B).

\section{Factors associated with viral suppression among HIV patients on treatment}

In a univariate logistic regression model, being diagnosed in WHO stage I, having good and fair adherence to ART, taking TDF/3TC/EFV, AZT/3TC/EFV or AZT/3TC/NVP and increasing duration of treatment were 
significantly associated with higher odds of attaining viral suppression compared to WHO stage IV, bad adherence to ART, taking Integrase based-regimen, and treatment for less than one year respectively.

After adjusting for possible cofounders in a multivariate logistic regression model, being diagnosed at WHO stage I [aOR $=14.26,95 \% \mathrm{Cl}(4.20-48.44), p<0.0001]$, having good adherence to ART [aOR $=5.64$, $95 \% \mathrm{Cl}(2.86-11.13), p<0.0001]$, being treated with TDF/3TC/EFV [aOR $=3.00,95 \% \mathrm{Cl}(1.15-7.78)$, $p=0.0240], \mathrm{AZT} / 3 \mathrm{TC} / \mathrm{EFV}[\mathrm{aOR}=6.83,95 \% \mathrm{Cl}(1.83-25.45), p=0.0040]$ or $\mathrm{AZT} / 3 \mathrm{TC} / \mathrm{NVP}[\mathrm{aOR}=5.16,95 \%$ $\mathrm{Cl}$ (1.33-19.94), $p=0.0170$ ] and increasing duration of treatment were independently associated with increased odds of viral suppression. However, ever stopping or changing ARV [aOR $=0.20,95 \% \mathrm{Cl}(0.05-$ $0.70), p=0.0190$ ] was significantly associated with lower odds of viral suppression (Table 3 ) 
Table 3

Predictors of viral suppression among HIV patients on CART.

\section{VARIABLE}

WHO stage of HIV

Stage I

$224(40.9)$

(\%)]

Stage II

Stage III

Stage IV

Adherence to ART

Good

$326(59.5)$

$175(31.9)$

$47(8.6)$

Poor

Ever stopped or changed ARV

No

Yes

\section{Common ARV combinations}

$(n=532)$

TDF/3TC/EFV

AZT/3TC/EFV

TDF/3TC/NVP

AZT/3TC/NVP

TDF/3TC/LPV/r

TDF/3TC/DTG

\section{Duration of ARV treatment (years)}

$<1$

1
aOR (95\% Cl)

p-value
$11.40(3.54-36.74)$

$2.13(0.71-6.42)$

$1.32(0.45-3.89)$

Ref (1)
$<$

0.0001

$1.78(0.95-3.35)$

0.0720

Ref (1)
0.0001

0.1800

0.6100 


\begin{tabular}{|c|c|c|c|}
\hline VARIABLE & $\begin{array}{l}\text { Viral Suppression [n } \\
(\%)]\end{array}$ & aOR (95\% Cl) & $p$-value \\
\hline 2 & $204(37.2)$ & $38.04(11.52-125.61)$ & $\hat{0}_{0.0001}$ \\
\hline 3 & 207 (37.8) & $79.93(23.08-276.78)$ & <. 0001 \\
\hline 4 & $27(4.9)$ & $\begin{array}{l}179.82(17.21- \\
1879.35)\end{array}$ & $<0.0001$ \\
\hline \multicolumn{4}{|c|}{$\begin{array}{l}\text { HIV; Human Immunodeficiency virus, WHO; world health organization, ARV; antiretroviral, cART; } \\
\text { combination antiretroviral therapy, TDF; tenofovir, 3TC; lamivudine, EFV; efavirenz, ABC; abacavir, FTC } \\
\text { emtricitabine, NVP; nevirapine, AZT; zidovudine, LPV/r; lopinavir/ritonavir, DTG; dolutegravir. }\end{array}$} \\
\hline
\end{tabular}

\section{Factors associated with viral rebound among HIV patients on treatment}

In a multivariate logistic regression model, being diagnosed at WHO stage II (aOR $=7.39,95 \%$ Cl: 2.67 $20.51 ; p<0.0001)$ and WHO stage III (aOR = 8.62, 95\% Cl: 3.16-23.50; $p<0.0001)$, having fair $(\mathrm{aOR}=8.71$, $95 \% \mathrm{Cl}: 3.96-19.18 ; p<0.0001)$, or poor adherence (aOR $=175.48,95 \% \mathrm{Cl}: 44.30-695.07 ; p<0.0001)$, recording a baseline viral suppression value of 20-49copies $/ \mathrm{mL}(\mathrm{aOR}=6.43,95 \% \mathrm{Cl}: 2.72-15.17 ; p<$ $0.0001)$, being treated with AZT/3TC/EFV $(\mathrm{aOR}=6.49,95 \% \mathrm{Cl}: 1.85-22.79 ; p=0.0040)$ or $\mathrm{AZT} / 3 \mathrm{TC} / \mathrm{NVP}$ $(\mathrm{aOR}=18.68,95 \% \mathrm{Cl}: 1.58-220.90 ; p=0.02)$, obtaining durability of ARVs viral suppression for up to 24 months $(\mathrm{aOR}=4.63,95 \% \mathrm{Cl}$ : $(1.34-24.48) ; p<0.0001)$ were independently associated with higher odds of viral rebound.

However, being diagnosed in WHO stage IV, having other conditions or opportunistic infections, recording baseline suppression value less than 20 copies $/ \mathrm{mL}$, ever stopped or changed ARV were not significantly associated with HIV viral rebound [Table 4]. 
Table 4

Factors Associated with Viral rebound among HIV Patients on treatment

\begin{tabular}{llll} 
Variable & Viral Rebound [n (\%)] & aOR (95\% Cl) & $p$-Value \\
\hline WHO stage of HIV & & & \\
Stage I & $15(13.0)$ & Ref $(1)$ & - \\
\hline Stage II & $37(32.2)$ & $7.39(2.67-20.51)$ & $<0.0001$ \\
\hline Stage III & $60(52.2)$ & $8.62(3.16-23.50)$ & $<0.0001$ \\
\hline Stage IV & $3(2.6)$ & $4.01(0.47-34.06)$ & 0.2040 \\
\hline Adherence to ART & & & \\
\hline Good & $20(17.4)$ & Ref $(1)$ & - \\
\hline Fair & $59(51.3)$ & $8.71(3.96-19.18)$ & $<0.0001$ \\
\hline Poor & $36(31.3)$ & $175.48(44.30-695.07)$ & $<0.0001$ \\
Presence of other condition $(\mathbf{s})$ & & & - \\
No & $94(81.7)$ & Ref $(1)$ & 0.1550 \\
Yes & $21(18.3)$ & $1.99(0.77-5.14)$ &
\end{tabular}

Presence of opportunistic infection (s)

\begin{tabular}{llll} 
No & $94(81.7)$ & Ref $(1)$ & - \\
\hline Yes & $21(18.3)$ & $1.23(0.39-3.90)$ & 0.7210
\end{tabular}

Baseline suppression category

$\begin{array}{llll}\text { Target not detected } & 26(22.8) & \text { Ref }(1) & - \\ <20 & 23(20.2) & 1.62(0.65-3.99) & 0.2990 \\ 20-49 & 65(57.0) & 6.43(2.72-15.17) & <0.0001\end{array}$

Ever stopped or changed ARV

\begin{tabular}{llll} 
No & $97(84.3)$ & Ref $(1)$ & - \\
\hline Yes & $18(15.7)$ & $1.61(0.45-5.73)$ & 0.4600
\end{tabular}

\section{Common ARV combinations}

TDF/3TC/EFV

$46(40.0) \quad \operatorname{Ref}(1)$

Adjusted for age and gender, $\mathrm{HIV}=$ Human Immunodeficiency virus, $\mathrm{WHO}=$ world health organization, $A R V=$ antiretroviral, $c A R T=$ combination antiretroviral therapy, $T D F=$ tenofovir, $3 T C=$ lamivudine, $E F V=$ efavirenz, ABC= abacavir, FTC; emtricitabine, NVP; nevirapine, AZT; zidovudine, LPV/r; lopinavir/ritonavir, DTG; dolutegravir, $\mathrm{cOR}=$ crude odd ratio, aOR= adjusted odd ratio, $\mathrm{Cl}=$ confidence interval, $p$-value of $<0.05$ was considered statistically significant. 


\begin{tabular}{|c|c|c|c|}
\hline Variable & Viral Rebound [n (\%)] & aOR $(95 \% \mathrm{Cl})$ & $p$-Value \\
\hline AZT/3TC/EFV & $22(19.1)$ & $6.49(1.85-22.79)$ & 0.0040 \\
\hline TDF/3TC/NVP & $8(7.0)$ & $3.48(0.53-22.87)$ & 0.1950 \\
\hline AZT/3TC/NVP & $24(20.9)$ & $18.68(1.58-220.90)$ & 0.0200 \\
\hline $\mathrm{TDF} / 3 \mathrm{TC} / \mathrm{LPV} / \mathrm{r}$ & $8(7.0)$ & $2.26(0.56-9.19)$ & 0.2520 \\
\hline TDF/3TC/DTG & $1(0.9)$ & $0.21(0.02-2.26)$ & 0.1990 \\
\hline \multicolumn{4}{|c|}{ Durability of ARV (Months) } \\
\hline $0-6$ & $36(31.3)$ & $8.87(2.92-31.36)$ & $<0.0001$ \\
\hline $7-12$ & $34(29.6)$ & $6.70(2.23-22.91)$ & $<0.0001$ \\
\hline $13-24$ & $34(29.6)$ & $4.63(1.34-24.48)$ & $<0.0001$ \\
\hline $25-36$ & $9(7.8)$ & $3.68(0.75-13.21)$ & 0.09400 \\
\hline $37-48$ & $2(1.7)$ & $\operatorname{Ref}(1)$ & - \\
\hline \multicolumn{4}{|c|}{$\begin{array}{l}\text { Adjusted for age and gender, HIV= Human Immunodeficiency virus, WHO= world health organization, } \\
\text { ARV= antiretroviral, cART = combination antiretroviral therapy, TDF= tenofovir, } 3 T C==\text { lamivudine, EFV }= \\
\text { efavirenz, ABC= abacavir, FTC; emtricitabine, NVP; nevirapine, AZT; zidovudine, LPV/r; } \\
\text { lopinavir/ritonavir, DTG; dolutegravir, cOR= crude odd ratio, aOR= adjusted odd ratio, Cl= confidence } \\
\text { interval, } p \text {-value of }<0.05 \text { was considered statistically significant. }\end{array}$} \\
\hline
\end{tabular}

\section{Discussion}

Human Immunodeficiency Virus/Acquired Immune Deficiency Syndrome (HIV/AIDS) is a leading cause of death worldwide. The fight against HIV/AIDS is hinged on initiation and adherence to an effective Antiretroviral Therapy (ART), and this has increased the attainment of viral suppression and reduction in HIV/AIDS-related death. Unfortunately, some people who achieve viral suppression are unable to maintain it and experience viral rebound, increasing their risk of treatment failure and the potential for transmission.

The United Nation's principal goal for eradicating HIV/AIDS by 2030 involves expanding access to and coverage of ART across the globe and viral suppression [24-26]. However, global assessment has shown that only around half of the world's HIV patients on ART are currently virally suppressed $[25,27]$. In the present study, the proportion of patients who attained viral suppression was $76.1 \%$. Consistent but quite higher than our study finding, Lebelonyane et al. [28] and Koss et al. [29], reported viral suppression among $82 \%$ of PLWH in Botswana and $80.7 \%$ among those in Uganda $[28,29]$. Our study finding is higher compared to studies by Lokpo et al. [30] and Maina et al. [11], who reported $69 \%$ and $59 \%$ viral suppression rate among patients in the Volta region of Ghana and Kenya respectively [11,30]. Again, viral suppression rate observed in our study is much higher compared to $24 \%$ in Sierra Leone and $41 \%$ in Senegal [25]. Although the $90 \%$ UNAIDS target for viral suppression is much higher than what was found 
in this study, our results provide a glimpse into the country's progression towards the UNAIDS 90-90-90 agenda.

We explored the factors associated with viral suppression among patients on ART. We observed that being diagnosed with WHO stage I, having good adherence to ART, being on a Nevirapine-based regimen and increasing duration of treatment with ARV were independently associated with higher chances of viral suppression. However, stopping or changing ARVs was associated with lower chances of viral suppression. Our findings are comparable to those observed by Maina et al. [11], who reported WHO stage I of HIV infection and good adherence to ART were associated with an increased likelihood of viral suppression [11]. Moreover, a study by O'Connor et al. [31], who found good ART adherence, and being diagnosed in WHO stage I were associated with viral suppression. The findings for WHO stage I being associated with high chances of viral suppression could be attributed to the initial infection stage of the virus and less downregulation of the immune system at this stage, making the body's natural immune system still responsive to infection.

In our study, increasing duration of treatment was associated with higher chances of viral suppression, consistent with a study by Kiselinova et al. [32] in the United Kingdom. This supports evidence from clinical studies that suggests prolonged cART use can reduce viral load below the limit of detection for a long-term period [33]. Moreover, stopping or changing ARVs was associated with lower chances of viral suppression. A similar finding was reported by Martínez et al. [34] and Maman et al. [35], who observed that switching HIV patients from a protease inhibitor to nevirapine, efavirenz, or abacavir resulted in a higher rate of virologic failure [34,35]. Hence, the type of CARV regimen may influence viral suppression and the risk of viral rebound.

Viral rebound increases vulnerability to illness, treatment failure, ART resistance, and the potential for HIV transmission [36, 37]. In the current study, viral rebound occurred in $21.0 \%$ of our patients. Our study finding is comparable but much higher than findings of Craw et al. [38], who reported 7.5\% viral rebound rate among American HIV patients who had achieved viral suppression [38]. In Kenya, among PLWH, viral rebound was $41 \%$ [11]. This implies that a considerable number of HIV patients who achieve viral suppression are unable to remain suppressed and therefore experience rebound episodes. This may contribute to some of the reasons why Ghana could not achieve the UNAIDS agenda 90-90-90 target in 2020.

We evaluated a number of putative factors associated with viral rebound. In the current study, we observed that patients diagnosed at WHO stage II and stage III had higher chances of viral rebound compared to those diagnosed at WHO stage I. Our study finding is in harmony with a study by Maina et al. [11], who reported that being diagnosed at WHO stage II is associated with higher viral rebound [11]. These findings suggests that patients at WHO stage II and above have downregulated immune system with associated opportunistic infections and comorbidities, increasing their venerability to viral rebound [39]. 
Notably, we observed that poor adherence was associated with higher viral rebound. Consistent with our study findings, Bulage et al. [40] reported higher viral rebound among HIV patients who experience rebound episodes. Among Kenyan HIV patients, Maina et al. [11], reported that poor ART adherence is associated with viral rebound [11]. The agreement between the current and previous studies may explain why majority of non-adherent HIV patients are vulnerable to illness, experience treatment failure and ART resistance [36, 37]. Furthermore, we observed that patients who recorded a baseline viral suppression value of 20-49 copies/ $\mathrm{mL}$ had higher chances of viral rebound compared to those who had target not detected. Consistent with our study finding, Palmer et al.[41], reported that baseline suppression count is associated with viral rebound [41]. Among Chinese HIV patients, Li et al. [42], reported similar association of baseline suppression value and viral rebound [42]. This finding is suggestive that patients with the lowest levels of viral load to the target not detected are more stable and unlikely to experience viral rebound.

Moreover, we observed that patients on Zidovudine based-regimen (AZT/3TC/EFV and AZT/3TC/NVP) had higher chances of viral rebound compared to patients on Tenofovir based-regimen (TDF/3TC/EFV). This is in line with a study by Mania et al. [11], who observed that AZT/ 3TC/NVP regimen was associated with high viral rebound. NNRTI- and NRTI-based regimens have increased risk of resistance within the first six months of treatment [43].

Our study provides useful findings to guide HIV clinicians and policy makers in the fight against the infection. However, it is limited by the fact that it was a retrospective study and single-centered. We relied on available hospital data, especially patients' viral load results, which posed a challenge to completeness of data.

\section{Conclusion}

The viral suppression rate among HIV patients on CART in Kumasi (76\%) do not meet the WHO target (90\%). Good adherence to ART, being on Nevirapine-based regimen and increasing duration of treatment with ARV independently leads to viral suppression. However, being diagnosed at WHO stage II and stage III, having bad to fair adherence, recording baseline suppression value of 20-49 copies/ $\mathrm{ml}$ and being treated with AZT/3TC/EFV and AZT/3TC/NVP leads to viral rebound. These clinical characteristics of HIV patients, associated with viral suppression and viral rebound must be monitored concurrently with the viral load.

\section{Abbreviations}

HIV: Human Immunodeficiency virus; WHO: World Health Organization; ARV: Antiretroviral; cART= Combination Antiretroviral Therapy; TDF: Tenofovir, 3TC: Lamivudine; EFV= Efavirenz; ABC: Abacavir, FTC: Emtricitabine; NVP: Nevirapine; AZT: Zidovudine; LPV/r: Lopinavir/ritonavir DTG; Dolutegravir; CHRPE: Committee on Human Research, Publication and Ethics; KATH: Komfo Anokye Teaching Hospital; KNUST: Kwame Nkrumah University of Science and Technology. 


\section{Declarations}

Acknowledgements

The authors are grateful to staff of the Komfo Anokye Teaching Hospital as well as research assistants and volunteers who contributed in diverse ways to the successful implementation of the study.

\section{Ethics Approval and consent to participate}

The study was approved by The Committee on Human Research, Publication and Ethics, School of Medical Sciences, Kwame Nkrumah University of Science and Technology (CHRPE/SMS/KNUST: CHEPE/AP/238/20). A thorough explanation of the study protocol and assurance of anonymity was made to the subjects. Written informed consent was also sought from participants and healthcare management before data and sample collection. All methods were carried out in accordance with relevant guidelines and regulations.

\section{Consent for Publications}

Not Applicable.

\section{Availability of Data and Materials}

All data generated or analyzed during this study are included in this article and its supplementary information files data and can be requested from corresponding author.

\section{Competing Interests}

Authors have declared that no conflicts of interest exist.

\section{Funding}

This study did not receive funding from private, government or non-for profit organization and was fully funded by authors.

\section{Authors' contributions}

SO, SAS, NKAB and ES conceived, conceptualized, and designed the study. SO, SAS, NKAB, AKE, ES and ROA reviewed and critiqued the study protocol. SO, ES, ROA, BDA, DAO, DNW, FOA, CBO and ADS participated in data collection. SO, ES, SAS and ROA analyzed the data. SO, ES, SAS, NKAB drafted the manuscript, and SO, SAS, NKAB, AKE, ES, ROA, BDA, DAO, DNW, FOA, CBO and ADS reviewed the manuscript. All authors read and approved the final manuscript.

\section{Authors' Information}

Not Applicable 


\section{References}

1. Murray CJ, Ortblad KF, Guinovart C, Lim SS, Wolock TM, Roberts DA, et al. Global, regional, and national incidence and mortality for HIV, tuberculosis, and malaria during 1990-2013: a systematic analysis for the Global Burden of Disease Study 2013. 2014;384(9947):1005-70.

2. Wang H, Wolock TM, Carter A, Nguyen G, Kyu HH, Gakidou E, et al. Estimates of global, regional, and national incidence, prevalence, and mortality of HIV, 1980-2015: the Global Burden of Disease Study 2015. 2016;3(8):e361-e87.

3. HIV/AIDS. JUNPo. Report on the Global Acquired Immunodeficiency Syndrome Epidemic: Unaids; 2008.

4. Author GACJA. Summary of the 2018 sentinel survey report. 2019.

5. Jamieson D, Kellerman SEJJotIAS. The 909090 strategy to end the HIV Pandemic by 2030: Can. the supply chain handle it? 2016;19(1):20917.

6. HIV/AIDS JUNPo. Geneva: UNAIDS; 2019.[Google Scholar]. 2018.

7. HIV UG. AIDS statistics-2018 fact sheet. 2019.

8. Barry O, Powell J, Renner L, Bonney EY, Prin M, Ampofo W, et al. Effectiveness of first-line antiretroviral therapy and correlates of longitudinal changes in CD4 and viral load among HIVinfected children in Ghana. 2013;13(1):476.

9. Smith C, Phillips A, Dauer B, Johnson M, Lampe F, Youle M, et al. Factors associated with viral rebound among highly treatment-experienced HIV-positive patients who have achieved viral suppression. HIV medicine. 2009;10(1):19-27.

10. Havlir DV, Hellmann NS, Petropoulos CJ, Whitcomb JM, Collier AC, Hirsch MS, et al. Drug susceptibility in HIV infection after viral rebound in patients receiving indinavir-containing regimens. Jama. 2000;283(2):229-34.

11. Maina E, Mureithi H, Adan A, Muriuki J, Lwembe R, Bukusi E. Incidences and factors associated with viral suppression or rebound among HIV patients on combination antiretroviral therapy from three counties in Kenya. International Journal of Infectious Diseases. 2020;97:151-8.

12. Arnsten JH, Demas PA, Grant RW, Gourevitch MN, Farzadegan H, Howard AA, et al. Impact of active drug use on antiretroviral therapy adherence and viral suppression in HIV-infected drug users. 2002;17(5):377-81.

13. Kassa D, Gebremichael G, Alemayehu Y, Wolday D, Messele T, van Baarle, DJAr, et al. Virologic and immunologic outcome of HAART in Human Immunodeficiency Virus (HIV)-1 infected patients with and without tuberculosis (TB) and latent TB infection (LTBI) in Addis Ababa. Ethiopia. 2013;10(1):18.

14. Horter S, Thabede Z, Dlamini V, Bernays S, Stringer B, Mazibuko S, et al. Life is so easy on ART, once you accept it": Acceptance, denial and linkage to HIV care in Shiselweni. Swaziland. 2017;176:52-9.

15. UNAIDS U. Factsheet: global AIDS update. 2019. UNAIDS Geneva; 2019.

16. Craw JA, Beer L, Tie Y, Jaenicke T, Shouse RL. Prejean JJJoAIDS. Viral rebound among persons with diagnosed HIV who achieved viral suppression, United States. 2020. 
17. Palmer A, Gabler K, Rachlis B, Ding E, Chia J, Bacani N, et al. Viral suppression and viral rebound among young adults living with HIV in Canada. Med (Baltim). 2018;97(22):e10562. doi:10.1097/md.0000000000010562. PubMed PMID: 29851775. Epub 2018/06/01.

18. Geretti AM, Smith C, Haberl A, Garcia-Diaz A, Nebbia G, Johnson M, et al. Determinants of virological failure after successful viral load suppression in first-line highly active antiretroviral therapy. Antivir Ther. 2008;13(7):927-36.

19. Adams JW, Marshall BD, Salleh NAM, Barrios R, Nolan S, Milloy M-J. Receipt of opioid agonist treatment halves the risk of HIV-1 RNA viral load rebound through improved ART adherence for HIVinfected women who use illicit drugs. Drug Alcohol Depend. 2020;206:107670.

20. Schmidt D, Kollan C, Stoll M, Hamouda O, Bremer V, Kurth T, et al. Everything counts-a method to determine viral suppression among people living with HIV using longitudinal data for the HIV care continuum-results of two large, German, multi-center real-life cohort studies over 20 years (19992018). BMC Public Health. 2021;21(1):1-17.

21. Landovitz R. What's the best way to measure ART adherence. Journal Watch. 2011;23(3).

22. Suryana K, Suharsono H, Antara IGPJ. Factors associated with adherence to anti-retroviral therapy among people living with HIV/AIDS at Wangaya Hospital in Denpasar, Bali, Indonesia: A CrossSectional Study. Hiv/aids (Auckland, NZ). 2019;11:307.

23. O'Connor J, Smith C, Lampe FC, Johnson MA, Chadwick DR, Nelson M, et al. Durability of viral suppression with first-line antiretroviral therapy in patients with HIV in the UK: an observational cohort study. The Lancet HIV. 2017;4(7):e295-302.

24. JUNPo HIV/AIDS, Organization WH. Epidemiological fact sheets on HIV/AIDS and sexually transmitted infections. 2004.

25. UNAIDS. UNAIDS Data 2018, Geneva UNAIDS. Switzerland,. 2018.

26. Bezabhe WM, Chalmers L, Bereznicki LR, Peterson GM. Adherence to antiretroviral therapy and virologic failure: a meta-analysis. Medicine. 2016;95(15).

27. WHO. Key Facts on HIV/AIDS, WHO, Geneva. Switzerland,. 2018.

28. Lebelonyane R, Bachanas P, Block L, Ussery F, Alwano MG, Marukutira T, et al. To achieve 95-95-95 targets we must reach men and youth: High level of knowledge of HIV status, ART coverage, and viral suppression in the Botswana Combination Prevention Project through universal test and treat approach. PLOS ONE. 2021;16(8):e0255227. doi:10.1371/journal.pone.0255227.

29. Koss CA, Natureeba P, Kwarisiima D, Ogena M, Clark TD, Olwoch P, et al Viral Suppression and Retention in Care up to 5 Years After Initiation of Lifelong ART During Pregnancy (Option B+) in Rural Uganda. Journal of acquired immune deficiency syndromes (1999). 2017;74(3):279-84. doi: 10.1097/QAI.0000000000001228. PubMed PMID: 27828878.

30. Lokpo SY, Ofori-Attah PJ, Ameke LS, Obirikorang C, Orish VN, Kpene GE, et al. Viral Suppression and Its Associated Factors in HIV Patients on Highly Active Antiretroviral Therapy (HAART): A Retrospective Study in the Ho Municipality, Ghana. AIDS Research Treatment. 2020;2020:9247451. doi:10.1155/2020/9247451. 
31. O'Connor J, Smith C, Lampe FC, Johnson MA, Chadwick DR, Nelson M, et al. Durability of viral suppression with first-line antiretroviral therapy in patients with HIV in the UK: an observational cohort study. The Lancet HIV. 2017;4(7):e295-302. doi:https://doi.org/10.1016/S23523018(17)30053-X.

32. Kiselinova M, Geretti AM, Malatinkova E, Vervisch K, Beloukas A, Messiaen P, et al. HIV-1 RNA and HIV-1 DNA persistence during suppressive ART with PI-based or nevirapine-based regimens. J Antimicrob Chemother. 2015;70(12):3311-6. doi:10.1093/jac/dkv250.

33. Resino S, Resino R, Micheloud D, Gurbindo-Gutiérrez D, Léon JA, Ramos JT, et al. Long-term effects of highly active antiretroviral therapy in pretreated, vertically HIV type 1-infected children: 6 years of follow-up. Clin Infect Dis. 2006;42(6):862-9.

34. Negredo E, Cruz L, Paredes R, Ruiz L, Fumaz CR, Bonjoch A, et al. Virological, immunological, and clinical impact of switching from protease inhibitors to nevirapine or to efavirenz in patients with human immunodeficiency virus infection and long-lasting viral suppression. Clinical infectious diseases. 2002;34(4):504-10.

35. Martínez E, Arnaiz JA, Podzamczer D, Dalmau D, Ribera E, Domingo P, et al. Substitution of nevirapine, efavirenz, or abacavir for protease inhibitors in patients with human immunodeficiency virus infection. N Engl J Med. 2003;349(11):1036-46.

36. Maman D, Zeh C, Mukui I, Kirubi B, Masson S, Opolo V, et al. Cascade of HIV care and population viral suppression in a high-burden region of Kenya. AIDS. 2015;29(12):1557.

37. Palmer A, Gabler K, Rachlis B, Ding E, Chia J, Bacani N, et al. Viral suppression and viral rebound among young adults living with HIV in Canada. Medicine. 2018;97(22).

38. Craw JA, Beer L, Tie Y, Jaenicke T, Shouse RL, Prejean J. Viral Rebound Among Persons With Diagnosed HIV Who Achieved Viral Suppression, United States. Journal of acquired immune deficiency syndromes (1999). 2020;84(2):133-40. doi: 10.1097/QAI.0000000000002321. PubMed PMID: 32084054.

39. Dessie ZG, Zewotir T, Mwambi H, North D. Modeling viral suppression, viral rebound and statespecific duration of HIV patients with CD4 count adjustment: parametric multistate frailty model approach. Infectious diseases therapy. 2020;9(2):367-88.

40. Bulage L, Ssewanyana I, Nankabirwa V, Nsubuga F, Kihembo C, Pande G, et al. Factors associated with virological non-suppression among HIV-positive patients on antiretroviral therapy in Uganda, August 2014-July 2015. BMC Infect Dis. 2017;17(1):1-11.

41. Palmer A, Gabler K, Rachlis B, Ding E, Chia J, Bacani N, et al. Viral suppression and viral rebound among young adults living with HIV in Canada. Medicine. 2018;97(22):e10562-e. doi: 10.1097/MD.0000000000010562. PubMed PMID: 29851775.

42. Ren L, Li J, Zhou S, Xia X, Xie Z, Liu P, et al. Prognosis of HIV Patients Receiving Antiretroviral Therapy According to CD4 Counts: A Long-term Follow-up study in Yunnan, China. Sci Rep. 2017;7(1):9595. doi:10.1038/s41598-017-10105-7. 
43. Meresse M, March L, Kouanfack C, Bonono RC, Boyer S, Laborde-Balen G, et al. Patterns of adherence to antiretroviral therapy and HIV drug resistance over time in the Stratall ANRS 12110/ESTHER trial in Cameroon. HIV Med. 2014;15(8):478-87. doi:10.1111/hiv.12140. PubMed PMID: 24589279. Epub 2014/03/05.

\section{Figures}

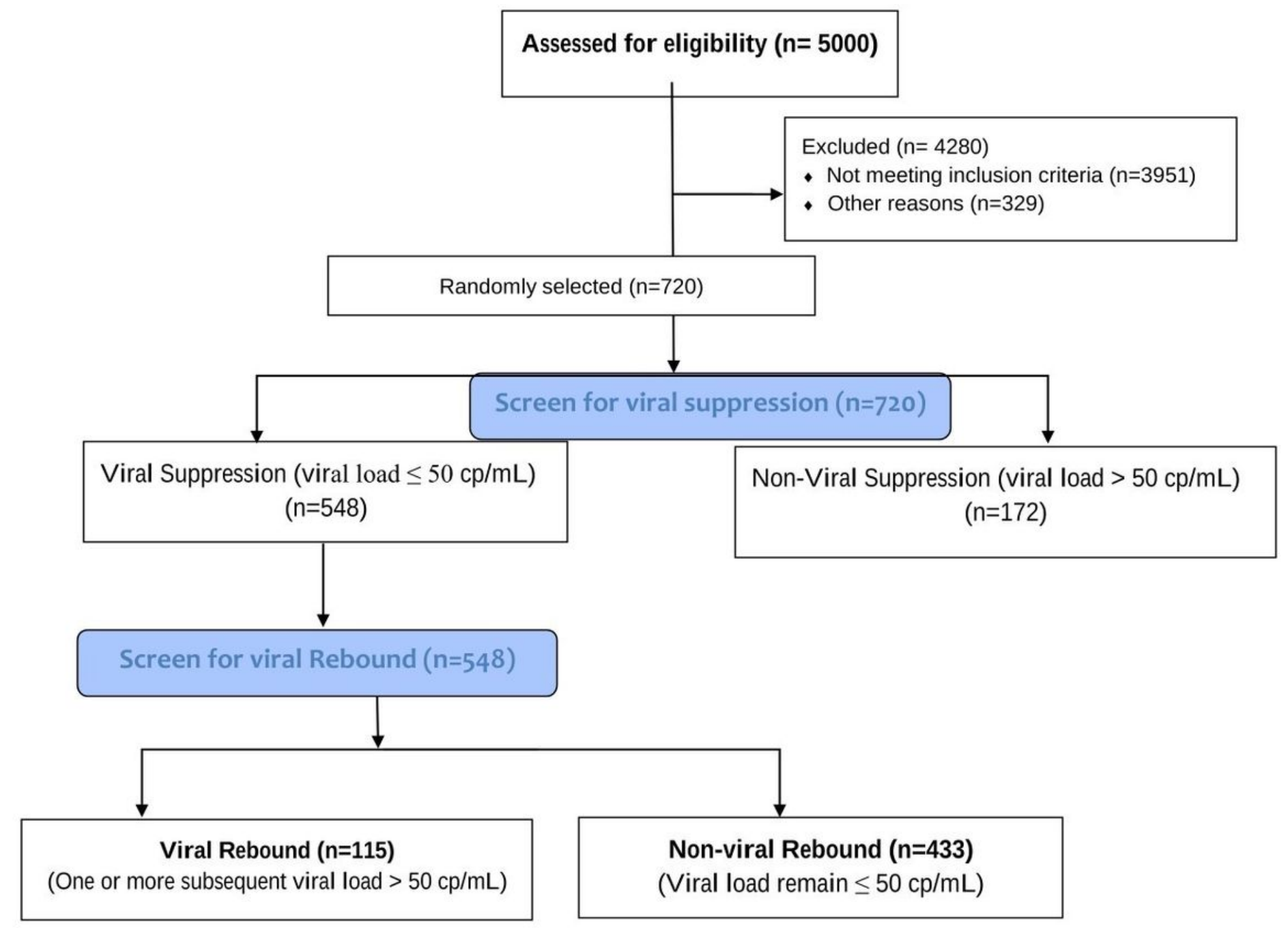

Figure 1

Consort Flow Chart 


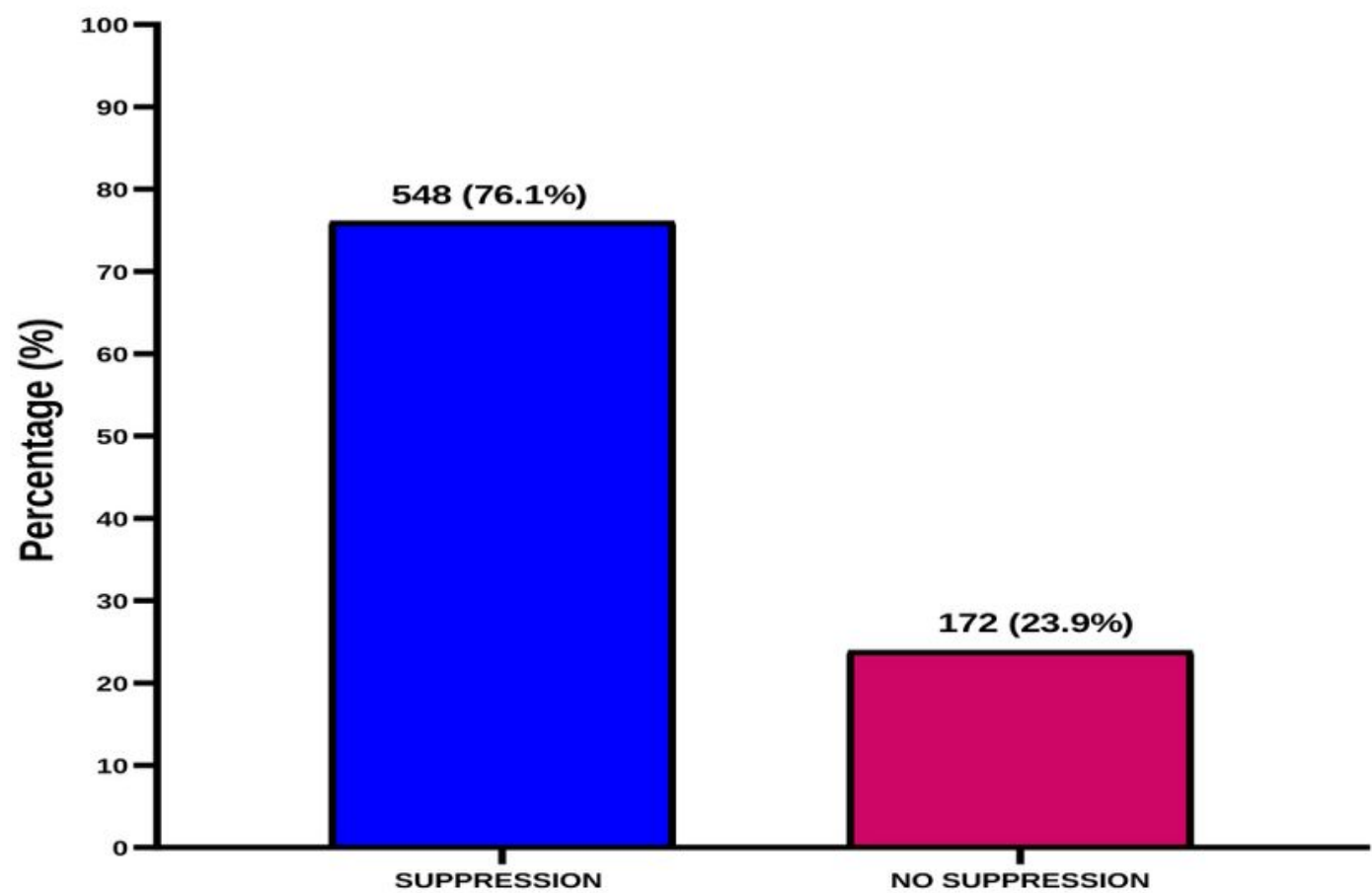

B

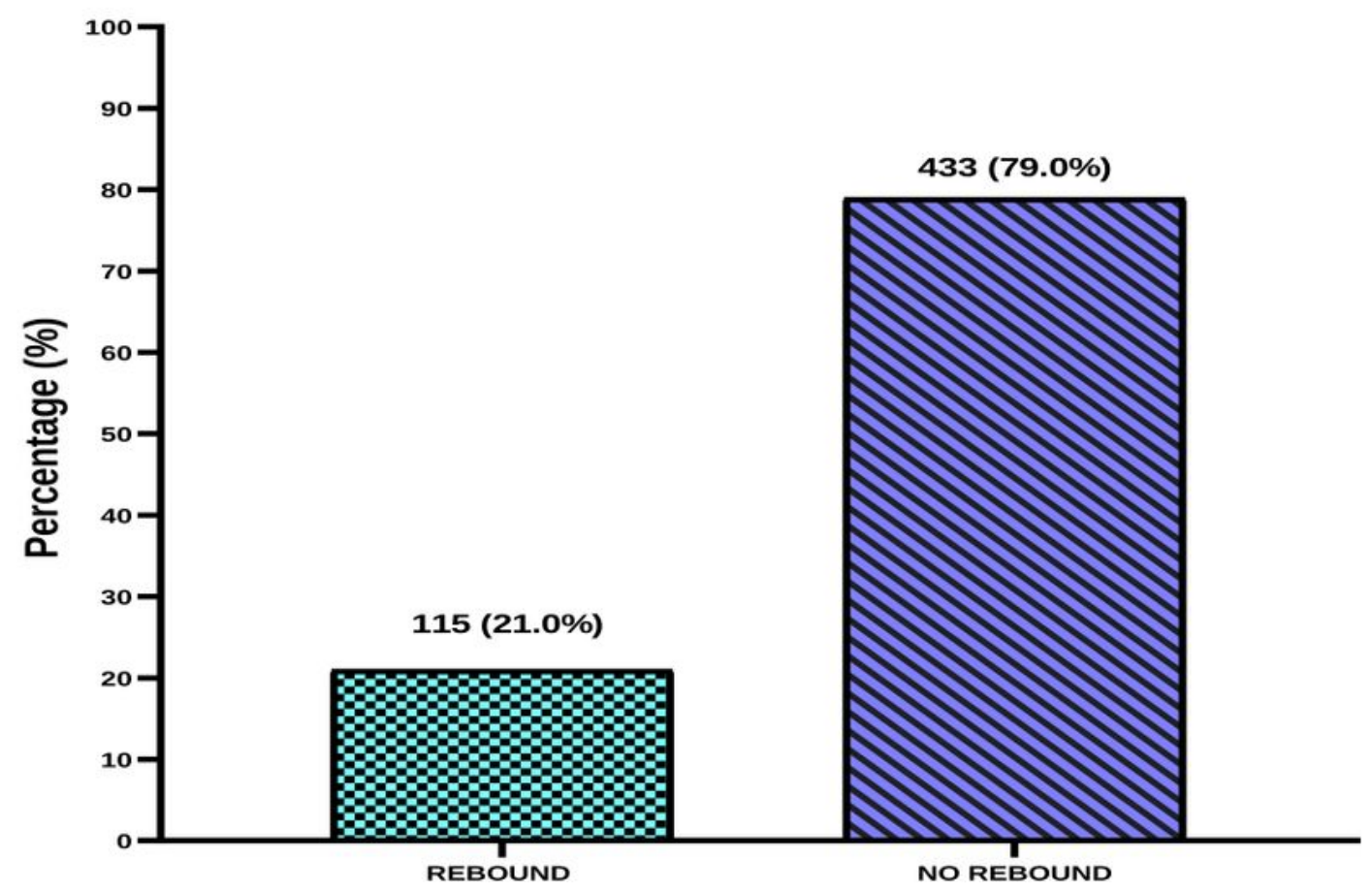

Figure 2

Viral suppression (A) and rebound (B) among HIV patients on treatment 